\title{
Vencedores e perdedores nas eleições presidenciais de 2014: o efeito da derrota nas urnas sobre a satisfação e o apoio em relação à democracia no Brasil ${ }^{1}$
}

Maria do Socorro Sousa Braga

Gabriel Avila Casalecchi

\section{Introdução $^{2}$}

A competição eleitoral está no âmago da democracia moderna. Em um Estado democrático os cidadãos vão às urnas de tempos em tempos para escolher seus representantes. O resultado é que, como em qualquer jogo, existem vencedores e perdedores. O que diferencia a democracia dos demais regimes é justamente a expectativa em torno desses grupos, especialmente o último. Espera-se que os perdedores aceitem a sua derrota e as regras do jogo na esperança de que possam vencê-lo em outra oportunidade.

A teoria da legitimidade democrática está ancorada nesse princípio. Em uma democracia os cidadãos não são obrigados a concordar sobre quem deve governar ou sobre como se deve governar. No entanto, deve haver consenso mínimo sobre as regras subjacentes à escolha dos governantes e, posteriormente, adesão aos resultados.

Nesse sentido, um importante sinal do quão legítima é a democracia de um país está no comportamento dos seus perdedores. Conforme defende Norris (1999), a avaliação crítica das instituições políticas e dos governantes pode perfeitamente conviver com a democracia, desde que o apoio a suas normas, regras e princípios seja conservado.

Talvez em nenhum outro momento da democracia brasileira a discussão sobre o papel dos perdedores seja tão relevante quanto após as últimas eleições presidenciais. No dia 26 de outubro de 2014, mais de 112 milhões de eleitores foram às urnas no segundo turno das eleições. A então presidenta Dilma Rousseff saiu vitoriosa na disputa do pleito contra Aécio Neves. Entretanto, mais que qualquer outra eleição pós-1988, a diferença foi extremamente pequena: Dilma teve $51,64 \%$ dos votos válidos enquanto Aécio obteve 48,36\%. Em números absolutos isso corresponde a cerca de 51 milhões de "perdedores"3.

\footnotetext{
${ }^{1}$ Este artigo insere-se no âmbito de projeto de pesquisa apoiado com bolsa de produtividade pelo Conselho Nacional de Desenvolvimento Científico e Tecnológico (CNPq).

2 Agradecemos aos pareceristas da revista Opinião Pública pelos ricos comentários e sugestões que muito ajudaram na discussão deste artigo. As limitações que ainda permanecerem são de nossa inteira responsabilidade.

3 Quanto às questões motivadoras deste artigo, cabe lembrar que esse resultado se refere à segunda reeleição do grupo político encabeçado pelo PT e que está no poder há 12 anos.
} 
Diante disso, o presente artigo tem duas indagações. Em primeiro lugar, ele investiga se a derrota nas urnas em 2014 afetou o apoio dos perdedores à democracia. Ou seja, perder as eleições fez com que os derrotados extrapolassem a crítica ao governo eleito, alcançando o próprio regime democrático e, portanto, as "regras do jogo"?

Além disso, também queremos compreender que condições são capazes de intensificar esse efeito. Ou seja, entendemos ser importante aprofundar as características que podem aumentar ou diminuir o gap entre vencedores e perdedores. No bojo das recentes manifestações e na emergência de um discurso autoritário por parcelas da população ${ }^{4}$, iremos, especificamente, observar os efeitos interativos provocados pela rejeição ao PT, pela percepção do desempenho econômico do país e, por fim, dos efeitos de quem vive em São Paulo, estado que tem sido palco de diversas manifestações e de uma pluralidade de discursos envolvendo não só o governo de Dilma, como também o próprio regime democrático.

Para encaminhar essa análise, estruturamos este artigo da seguinte maneira. Na próxima seção, "Enquadramento teórico", discutimos as principais teorias e estudos empíricos que contribuíram para a área do comportamento político alcançar os avanços obtidos no que diz respeito às atitudes políticas de perdedores e vencedores em relação à satisfação com o regime democrático e à adesão a este. Na terceira seção, "Variáveis, hipóteses e metodologia", descrevemos as variáveis, as hipóteses a serem checadas e a metodologia usada para modelagem estatística. Na quarta seção, "Resultados e discussão", desenvolvemos a análise dos resultados auferidos. $E$, na última seção, temos as "Considerações finais".

\section{Enquadramento teórico}

Do ponto de vista das instituições, as eleições estão no cerne da democracia. Apesar das várias definições (Collier e Levitsky, 1997), os estudiosos concordam que a escolha livre, periódica e competitiva dos líderes políticos é requisito necessário do regime democrático (Sartori, 1987; Dahl, 1997; Bobbio, 1990), ainda que não suficiente (Diamond, 1999; Mainwaring, Brinks e Pérez-Liñán, 2001). São as eleições que dão singularidade às democracias (Alvarez et al., 1996) ao mesmo tempo que proporcionam incentivos às elites em aceitar as regras do jogo, mesmo que nem sempre saiam vitoriosas (O'Donnell e Schmitter, 1988).

Ocorre que, para além do desenho institucional, o processo eleitoral traz uma outra consequência fundamental - porém ainda pouco investigada no Brasil - para o sistema político: a partição do eleitorado entre os "vencedores" e os "perdedores". Segundo

\footnotetext{
${ }^{4}$ Em sua pesquisa com participantes das manifestações do dia 15 de março e 12 de abril de 2015, Telles (2015) demonstra que, aliado à forte rejeição ao governo e à desconfiança dos partidos políticos, $50 \%$ dos manifestantes estariam dispostos a apoiar uma intervenção militar em caso de muita desordem política. Os que afirmaram de forma espontânea que a solução para os problemas do país seria uma intervenção militar chegaram a $15 \%$.
} 
Anderson e Guillory (1997, p. 68), se as eleições proporcionam às massas oportunidades iguais de participação, elas também produzem resultados inevitavelmente desiguais, na medida em que sempre haverá uma maioria vitoriosa e, inversamente, uma minoria perdedora.

Tanto quanto outras clivagens que dividem as sociedades, a distinção entre "vencedores" e "perdedores" afeta profundamente a forma como os cidadãos enxergam as instituições políticas. Do ponto de vista do jogo eleitoral, os vencedores seriam mais satisfeitos uma vez que o presidente, e/ou o partido, que representa os seus interesses seja eleito e suas preferências políticas sejam mais suscetíveis de ser promulgadas. Inversamente, os perdedores tendem a desconfiar de um governo para o qual não votaram. Nesse cenário, Anderson e Mendes (2005, p. 3) argumentam que são os derrotados que recebem os maiores incentivos para desejar uma mudança em relação ao status quo.

As pesquisas empíricas na área têm dado amplo suporte a essa tese sob diferentes perspectivas. Em uma pesquisa pioneira, Anderson e Guillory (1997) comparam os efeitos da derrota eleitoral sobre a satisfação com a democracia em sistemas majoritários e consensuais europeus (seguindo a definição de Lijphart, 1999). No nível individual, eles encontraram que os "perdedores" das eleições são menos satisfeitos com a democracia. No nível sistêmico esse processo seria mediado pelo "tipo" de democracia: nas majoritárias esse gap seria maior, uma vez que há menor inclusão de minorias no processo decisório.

Com base em 25 países do World Values Survey (WVS), de 1990 a 1993, Norris (1999) faz análise semelhante, dessa vez estudando o impacto dos perdedores sobre a confiança nas instituições políticas. O resultado, mais uma vez, dá suporte à tese de que a derrota nas eleições molda as atitudes dos cidadãos em relação às instituições democráticas: fazer parte dos "perdedores" aumenta, significativamente, as chances de desconfiar das instituições políticas.

Esses resultados são reforçados pela pesquisa longitudinal de Anderson e LoTempio (2002). Em um período que vai de 1972 a 1996, eles mostram, através do American National Electoral Studies, que os eleitores do presidente derrotado são, sistematicamente, mais desconfiados do governo. O estudo mostra ainda um ponto importante: votar no congressista vitorioso não atenua o efeito da desconfiança. Ou seja, em última instância, ao menos nos Estados Unidos, é a derrota presidencial que afeta a confiança.

Por fim, em uma nova e importante contribuição metodológica, a pesquisa de painel realizada por Singh, Karakoç e Blais (2012) demonstra um aumento na satisfação com a democracia entre aqueles que tiveram o seu partido selecionado para compor o governo: "nós mostramos que a inclusão de um dos partidos no governo é o fator mais importante para a satisfação com a democracia"5 (Singh, Karakoç e Blais, 2012, p. 202).

\footnotetext{
${ }^{5}$ Tradução livre de: "we show that the inclusion of one's selected party in government is the most important factor for satisfaction with democracy".
} 
A abundância de achados empíricos internacionais não é reproduzida no Brasil ou mesmo na América Latina, onde existem poucos estudos específicos a respeito do efeito do resultado eleitoral sobre as atitudes dos vencedores e perdedores. Há, no entanto, duas importantes exceções. Trabalhando com dados do Barômetro das Américas de 2008, Vairo (2012) demonstra que os eleitores que votaram em presidentes perdedores nas eleições mais recentes do país são mais insatisfeitos e apoiam menos a democracia do que os que votaram nos presidentes vitoriosos. Esse efeito é robusto mesmo quando controlado por variáveis sociodemográficas, econômicas, por outras atitudes políticas e até mesmo por variáveis políticas contextuais, como o nível de democracia do país. Outra exceção é o estudo de Rennó et al. (2011), que também utiliza os dados do Barômetro das Américas, porém para o ano de 2010. De acordo com os autores, os perdedores das eleições nacionais no Brasil, na Venezuela, no Equador e na Bolívia têm mais chances de estar insatisfeitos com a democracia, bem como de desconfiar das autoridades políticas. Entretanto, diferente de Vairo (2012), não encontraram um efeito significativo da derrota nas urnas sobre o apoio ao regime democrático.

Para além do efeito direto da derrota sobre as atitudes políticas, novos estudos têm discutido as condições que intensificam esse gap entre perdedores e vencedores. Isto é, eles têm argumentado que determinadas circunstâncias podem tanto minimizar os efeitos provocados pelo resultado das eleições, como também podem maximizá-los.

Seguimos aqui o argumento de Anderson et al.:

No nível mais básico, esperamos que as predisposições políticas dos indivíduos afetem a maneira como a experiência de ganhar e perder se traduz em diferentes graus de apoio ao sistema político. Em particular, argumentamos que os indivíduos podem manter predisposições que servem tanto para amplificar ou silenciar os efeitos positivos de ganhar e os efeitos negativos de perder $^{6}$ (Anderson et al., 2005, p. 74).

Mas quais seriam essas predisposições? Como existem poucos estudos a respeito, nosso artigo irá investigar essa questão ainda em caráter exploratório, identificando possíveis condições que, de maior ou menor maneira, possam ampliar ou restringir o impacto exercido pela derrota e pela vitória nas urnas sobre as atitudes democráticas.

Em uma das raras exceções quanto a esse tipo de estudo, Anderson et al. (2005) demonstram que posições ideológicas e partidárias extremas reforçam o efeito negativo da derrota em atitudes de apoio e de satisfação com a democracia. Essa seria, portanto, uma primeira hipótese a ser testada: de que o extremismo partidário reforça o efeito negativo exercido pela derrota sobre o apoio e a satisfação quanto à democracia.

\footnotetext{
${ }^{6}$ Tradução livre de: "At the most basic level, we expect that individuals' political predispositions affect how the experience of winning and losing translates into varying degrees of support for the political system. In particular, we argue that individuals may carry predispositions that can serve to amplify or mute the positive effects of winning and the negative effects of losing".
} 
Um segundo fator relevante está na percepção dos eleitores sobre o desempenho econômico do país. Inúmeros estudos têm mostrado o papel-chave dessa avaliação não só no voto como nas próprias atitudes que dizem respeito ao regime democrático e às suas instituições (McAllister, 1999; Mishler e Rose, 1999, 2001).

Acreditamos que esse conjunto de teorias é particularmente relevante para pensar o caso brasileiro, especialmente na atual conjuntura política, marcada pelo acirramento da polarização política de dois grandes partidos políticos - PT e PSDB - ao longo das sete últimas eleições desde o processo de redemocratização (Braga, 2006, 2010).

O Gráfico 1 mostra o acirramento da competição entre PT e PSDB nessas eleições. Nas duas primeiras, em 1994 e 1998, Fernando Henrique sagrou-se vitorioso ainda nos primeiros turnos das eleições, ficando logo à frente de Lula (que ficou na segunda posição), por $27,3 \%$ e $21,4 \%$ dos votos, respectivamente.

Em 2002, Lula chega a sua primeira vitória e, em 2006, conquista sua reeleição. Entretanto, ao contrário de FHC, o candidato petista precisa do segundo turno nas duas eleições para vencer, respectivamente, José Serra e Geraldo Alckmin, do PSDB. Em seguida Dilma é eleita em disputa no segundo turno com José Serra. A diferença do PT sobre os candidatos peessedebistas, que tinha sido de $22,6 \%$ e $21,6 \%$ nas eleições de 2002 e 2006 com Lula, caiu para 12,0\%, em 2010 com Dilma. Por fim, em 2014 temos a eleição mais acirrada da história, com a vitória de Dilma sobre Aécio Neves do PSDB, por apenas $3,2 \%$ dos votos.

\section{Gráfico 1}

Proporção de votos nas eleições de 1994 e 1998 ( $1^{\circ}$ turno) e 2002, 2006, 2010 e 2014 ( $2^{\circ}$ turno) (\%)

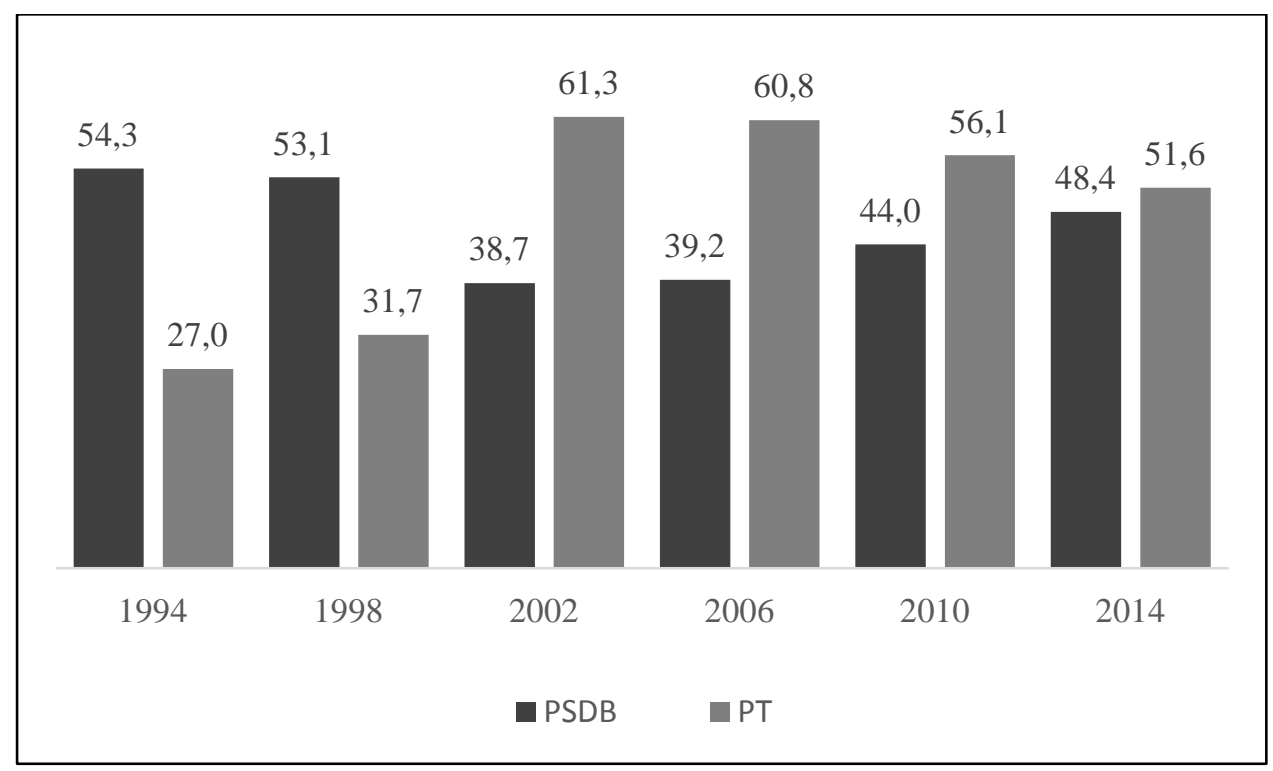

Fonte: TSE. 
Portanto, para além da importância teórica da discussão, acreditamos que, tendo em vista a atual conjuntura política brasileira marcada pelo acirramento entre os eleitores de ambos os partidos, é, mais do que nunca, pertinente uma análise mais profunda a respeito das atitudes dos perdedores e vencedores nas eleições de 2014.

\section{Variáveis, hipóteses e metodologia}

De forma geral, o presente artigo pretende testar o efeito de ter o candidato a presidente derrotado sobre as atitudes em relação à democracia. Mas que atitudes são essas? As pesquisas mais recentes têm utilizado diferentes variáveis ligadas a uma ideia multidimensional da legitimidade política: o apoio à comunidade e à democracia; a satisfação com o funcionamento da democracia; a confiança nas instituições, nos atores políticos e no governo local (Norris, 1999; Dalton, 2004; Booth e Seligson, 2009; Rennó et al., 2011).

Não utilizaremos aqui todas essas dimensões. Entretanto, seguimos essa linha de pesquisas - cuja tradição retoma os trabalhos de Easton (1965) - que separa o apoio político em duas dimensões: a difusa - referente aos princípios mais abstratos do sistema político - e a específica - que diz respeito ao seu funcionamento efetivo. Nesse sentido, optamos por duas variáveis tradicionais dos estudos de legitimidade: a adesão à democracia (dimensão difusa) e a satisfação com o seu desempenho (específica).

Levando-se em consideração o Eseb 2014, o percentual de satisfeitos com a democracia é de apenas $40 \%$, ou seja, mais da metade dos eleitores manifestam sua insatisfação com o funcionamento do regime. Já o percentual de apoio à democracia é maior, chegando aos $64 \%$. Esses percentuais confirmam uma tendência amparada por pesquisas anteriores, de que os brasileiros são, em sua maioria, adeptos do regime democrático, mas, ao mesmo tempo, são majoritariamente insatisfeitos com o seu desempenho prático.

Em segundo lugar, é preciso esclarecer a condição que separa os "vencedores" dos "perdedores". Estudos anteriores divergem quanto ao critério definidor da "derrota" ou da "vitória". Isso acontece porque existem eleições para diversos cargos, assim como competição no nível partidário. Ou seja, um eleitor pode ter seu candidato derrotado nas eleições para presidente, mas, ao mesmo tempo, eleger um governador, um deputado ou um senador. De forma ainda mais complexa, esse eleitor pode perder no que se refere a um cargo majoritário, entretanto o seu partido ou coligação pode compor maioria no legislativo.

Para o presente artigo, optou-se pelo critério do voto presidencial no segundo turno. Ou seja, quem votou, no segundo turno, no candidato que perdeu as eleições é considerado "perdedor", enquanto o que votou no vitorioso é o "vencedor". A escolha por 
esse critério se deve, basicamente, ao fato de que no Brasil são as eleições majoritárias nacionais que concentram visibilidade e polarização política.

Para garantir um modelo mais robusto, é importante controlar os (possíveis) efeitos do resultado das urnas por outras condições, igualmente relevantes para explicar a satisfação e a adesão em relação à democracia. Pode-se argumentar, por exemplo, que o que realmente importa não é a condição de perdedor, mas sim a avaliação negativa do governo, da economia ou a própria imagem do partido do eleitor. Uma segunda crítica é de que determinadas condições demográficas, sociais e individuais estejam ligadas ao perfil dos perdedores e que são essas condições, e não exatamente o fato de ser perdedor, o que importa.

Para contornar - tanto quanto possível - esse tipo de problema, realizamos uma análise multivariada de dados, com um modelo de regressão logística. Dessa forma, será possível dizer se existe uma relação entre os perdedores e as atitudes de apoio e satisfação quanto à democracia, mesmo quando controlada por uma série de condições. Essas variáveis de controle são: sexo, idade, estado em que vive, escolaridade, grau de religiosidade, exposição às informações políticas, interesse por política, avaliação do governo Dilma, avaliação da economia e, por fim, forte rejeição ao Partido dos Trabalhadores ${ }^{7}$.

A construção das variáveis que irão compor nosso modelo multivariado foi realizada conforme a descrição que segue:

Adesão à democracia. A variável foi construída a partir da seguinte pergunta: "algumas pessoas dizem que a democracia é sempre melhor que qualquer outra forma de governo. Para outros, em algumas situações é melhor uma ditadura do que uma democracia. Qual destas afirmações é mais parecida com sua forma de pensar? 1) A democracia é sempre melhor que qualquer outra forma de governo; 2) Em algumas situações é melhor uma ditadura do que uma democracia; 3) Tanto faz/Nenhuma das duas é melhor. As respostas foram recodificadas em uma variável binária em que os democratas são os que responderam a primeira opção e os não democratas os que responderam as alternativas restantes ou os que não responderam.

Satisfação com a democracia. A variável foi construída a partir da seguinte pergunta: "De uma maneira geral, o(a) sr(a). está muito satisfeito(a), satisfeito(a), pouco satisfeito(a) ou nada satisfeito com o funcionamento da democracia no Brasil? 1) Muito satisfeito(a); 2) Satisfeito(a); 3) Nem satisfeito(a), nem insatisfeito(a) (espontânea); 4) Pouco satisfeito(a); 5) Nada satisfeito. As respostas foram recodificadas em uma variável

\footnotetext{
7 Um teste de qui-quadrado demonstrou que algumas dessas variáveis independentes estão associadas, especialmente a insatisfação com a economia e a insatisfação com o governo. Entretanto, o teste de VIF (Variance Inflation Factor) demonstrou que nenhuma variável apresentou fator superior a 10, o que significa que não existe um problema significativo de multicolinearidade (Hair Jr. et al., 2009).
} 
binária em que os satisfeitos são os que responderam a primeira ou a segunda opções e os não satisfeitos, as alternativas restantes ou os que não responderam.

Muito religioso. A variável foi construída a partir da seguinte pergunta: "O(A) sr(a). se considera uma pessoa: 1) muito religiosa, 2) religiosa, 3) um pouco religiosa, 4) nada religiosa/". As respostas foram recodificadas em uma variável binária em que os muito religiosos são os que responderam a primeira alternativa e os pouco ou nada religiosos, os que responderam as demais alternativas ou que não responderam.

Exposto à informação. A variável foi construída a partir das seguintes perguntas, cujas respostas eram todas sim (1) e não (0): Essa semana o(a) sr(a). assistiu a algum telejornal de transmissão nacional, ou seja, que passa em todo o Brasil? E essa semana o(a) $\operatorname{sr}(a)$. assistiu a algum telejornal regional, ou seja, que passa notícias de sua cidade ou região? $\mathrm{O}(\mathrm{A}) \operatorname{sr}(a)$. ouviu notícias no rádio esta semana? As respostas foram, então, somadas e, posteriormente, recodificadas em uma variável binária em que o muito exposto à informação foi quem atingiu a pontuação máxima, ou seja, esteve exposto a todas as formas de informação, e o pouco ou nada informado foram todos os demais.

Interessado por política. A variável foi construída a partir da seguinte pergunta: "Quanto o(a) sr(a). se interessa por política? $O(A) \operatorname{sr}(a)$. diria que é: 1) muito interessado; 2) interessado; 3) pouco interessado; ou 4) nada interessado?". As respostas foram recodificadas em uma variável binária em que os interessados são os que responderam a primeira ou a segunda alternativa e os pouco ou nada interessados os que responderam as demais alternativas ou não responderam.

Avaliação negativa da economia. A variável foi construída a partir da seguinte pergunta: "Na sua opinião, a atual situação econômica do Brasil está melhor, igual ou pior, que 12 meses atrás? 1) Melhor; 2) Igual; 3) Pior". As respostas foram recodificadas em uma variável binária em que os que avaliam mal a economia são os que responderam a segunda e terceira alternativas e os que avaliam bem os que responderam a primeira alternativa.

Avaliação negativa do governo Dilma. A variável foi construída a partir da seguinte pergunta: "Na sua opinião, de uma maneira geral, o governo da presidente Dilma Rousseff nos últimos quatro anos foi: 1) Ótimo; 2) Bom; 3) Regular; 4) Ruim; ou 5) Péssimo". As respostas foram recodificadas em uma variável binária em que os que avaliam mal o governo são os que responderam a terceira, a quarta ou a quinta alternativas e os que avaliam bem o governo, os que responderam a primeira ou a segunda alternativa.

Forte rejeição ao PT. A variável foi construída a partir da seguinte pergunta: "Por favor, para cada partido que eu citar, gostaria que atribuísse uma nota de 0 a 10 , sendo que zero significa que o(a) sr(a). não gosta de jeito nenhum do partido e 10 que o(a) sr(a). gosta muito. Que nota você daria ao PT?". As respostas foram recodificadas em uma variável binária em que os que rejeitam fortemente o PT são os que deram a nota 0 , enquanto os que rejeitam pouco ou não rejeitam escolheram as demais notas. 
Para testar essas hipóteses utilizamos aqui os dados provenientes do Estudo Eleitoral Brasileiro (Eseb) de $2014^{8}$. O Eseb 2014 foi aplicado duas semanas após a realização do segundo turno desse pleito a uma amostra de 3.136 eleitores, sendo 2.506 entrevistas proporcionais em todo o território nacional e complemento de 630 entrevistas no estado de São Paulo. Dessa forma, esse estado tem uma amostra de 1.204 casos, que permite a leitura pelas variáveis "capital", "periferia" e "interior". A amostra nacional tem um nível de confiança estimado em 95\% e margem de erro máxima estimada em 2 pontos percentuais para mais ou para menos sobre os resultados encontrados no total da amostra.

\section{Resultados e discussão}

A Tabela 1 apresenta os resultados do modelo discutido na seção anterior, "Variáveis, hipóteses e metodologia". Quanto às variáveis sociodemográficas, confirma-se algo já encontrado em outros estudos: os homens são mais insatisfeitos, porém mais democráticos do que as mulheres (Rennó et al., 2011). Por outro lado, diferente de pesquisas prévias (Moisés e Carneiro, 2008), não encontramos qualquer relação entre a idade e a satisfação com a democracia e adesão a ela.

Outro resultado recorrente da literatura que também encontramos em nossa pesquisa é o efeito da escolaridade. Como esperado, os mais escolarizados são os que mais apoiam a democracia. Por outro lado, não encontramos nenhuma relação no que tange à satisfação com a democracia, o que contradiz pesquisas realizadas no Brasil (Moisés e Carneiro, 2008).

O efeito do interesse político não apresenta surpresas: quanto maior o interesse, maiores também as chances de satisfação com a democracia e adesão a ela. A exposição à informação política, por sua vez, apresenta um resultado peculiar: quanto maior a exposição mais chances de satisfação com o regime democrático, porém menos chances de adesão a ele.

Mas, de todas as variáveis sociodemográficas, a que mais chama a atenção por seu efeito é a de quem vive em São Paulo. Apesar de não exercer nenhum efeito sobre a

\footnotetext{
8 Observamos nas últimas décadas grande avanço no campo das pesquisas sobre comportamento político com a aplicação sistemática de surveys internacionais e nacionais. Vale aqui destacar entre os internacionais: Eurobarometer, New Europe Barometer, Latinobarometer, Afrobarometer, East Asian Barometer, Asianbarometer, European Values Studies (EVS), International Social Survey Program (ISSP), European Social Survey (ESS), Comparative Study of Electoral Systems (CSES) e World Values Survey (WVS). No caso brasileiro, destacamos o Estudo Eleitoral Brasileiro (Eseb), que, vinculado ao internacional CSES, tem sido aplicado periodicamente logo após o término de cada eleição presidencial desde 2002. Esse survey tem por pressuposto a defesa de que os contextos sociopolíticos e os arranjos institucionais influenciam a natureza e a qualidade da democracia. Nesse sentido, tem por objetivos primordiais "identificar como variáveis contextuais, especialmente as instituições eleitorais, moldam crenças e comportamentos dos cidadãos e, através de eleições, definem a capacidade ou a qualidade do regime democrático; compreender a natureza dos alinhamentos e clivagens sociais e políticos; compreender como cidadãos, vivendo sob distintos arranjos políticos, avaliam os processos políticos e as instituições democráticas" (Cesop, 2011).
} 
satisfação com a democracia, quem vive no estado tem menos chances de aderir à democracia do que quem vive em outro estado, isto é: os paulistas são mais autoritários ${ }^{9}$.

Esse resultado representa um desafio a ser explicado: por que justamente no estado mais rico e moderno do Brasil encontramos os cidadãos mais dispostos a acreditar que, em algumas circunstâncias, um regime autoritário é melhor que a democracia? Uma das explicações possíveis para esse comportamento do eleitor paulista está relacionada com a crescente rejeição ao Partido dos Trabalhadores em seu berço de origem, em particular, e ao aumento da desconfiança nas instituições democráticas, em geral. À medida que novos escândalos de corrupção foram envolvendo partidos da situação e da oposição, e em particular do PT, ampliou-se esse sentimento de rejeição aos partidos políticos.

Um resultado que merece ser aprofundado diz respeito às avaliações da economia e do governo Dilma Rousseff. Como esperado, quem acha que a economia não vai bem, e também avalia assim o atual governo, está mais insatisfeito com a democracia. A princípio, essa insatisfação não chega a ser nenhum problema e, como apontam alguns estudos, trata-se de uma situação típica e até mesmo "saudável" das democracias já estabelecidas.

O ponto que gostaríamos de enfatizar, no entanto, é que, além de provocar insatisfação, as avaliações negativas da economia e do governo afetam, também, a adesão à democracia. Ou seja, aqueles que avaliam negativamente essas áreas têm mais chances de rejeitar o regime democrático ou mesmo de ser indiferente em relação a ele.

Com todo o cuidado que a limitação de uma pesquisa com corte transversal impõe, esse resultado não deixa de servir de alerta para a democracia no Brasil. Não se trata, em absoluto, de um alarde sobre qualquer tipo de "crise da democracia", para usar uma expressão cunhada por Crozier, Huntington e Watanuki (1975). Como defendeu Easton (1965), as democracias têm uma "reserva de legitimidade" capaz de supor certa corrosão resultante dos períodos mais prolongados de insatisfação política e econômica. Entretanto, na medida em que os insatisfeitos são, também, mais autoritários, cria-se um ambiente favorável à proliferação de discursos antidemocráticos (ainda que nem sempre sejam explícitos).

Por fim, o resultado da nossa pergunta de pesquisa: os perdedores das eleições são mais insatisfeitos com a democracia do que os vitoriosos, porém não existem diferenças no que tange à adesão à democracia. Deve-se sublinhar que esse resultado é válido mesmo quando controlado por diferentes características demográficas, sociais e individuais, entre elas a avaliação do governo Dilma Rousseff e a rejeição ao PT. Ou seja, não eleger um

\footnotetext{
${ }^{9}$ Apesar dos resultados substantivos encontrados, é preciso deixar claro que a interpretação do resultado refere-se à comparação de São Paulo com os demais estados do país, limitando, dessa forma, a capacidade de interpretar com maior rigor quais características estão influenciando essa diferença. Acreditamos que essa questão mereça um maior esforço de análise, que não cabe no espaço deste artigo.
} 
candidato vitorioso aumenta as chances de insatisfação com a democracia, mas não interfere no apoio ao regime.

Tabela 1

Determinantes da satisfação e da adesão à democracia no Brasil - 2014 Modelo de regressão logística

\begin{tabular}{|l|c|c|c|c|}
\hline & \multicolumn{2}{|c|}{$\begin{array}{c}\text { Satisfação com a } \\
\text { democracia }\end{array}$} & \multicolumn{2}{c|}{$\begin{array}{c}\text { Adesão à } \\
\text { democracia }\end{array}$} \\
\hline & $\begin{array}{c}\text { Razão de } \\
\text { chance }\end{array}$ & $\begin{array}{c}\text { Erro-padrão } \\
\text { robusto }\end{array}$ & $\begin{array}{c}\text { Razão de } \\
\text { chance }\end{array}$ & $\begin{array}{c}\text { Erro-padrão } \\
\text { robusto }\end{array}$ \\
\hline Perdedores & $\mathbf{0 . 8 3 *}$ & $\mathbf{0 . 0 9 0}$ & $\mathbf{0 . 9 9}$ & $\mathbf{0 . 1 0 7}$ \\
\hline Homem & $1.26 * *$ & 0.114 & $1.29 * * *$ & 0.116 \\
\hline Idade em anos & 1.00 & 0.003 & 1.00 & 0.003 \\
\hline Mora em SP & 0.93 & 0.087 & $0.64 * * *$ & 0.058 \\
\hline Até o primário & Referência & Referência & Referência & Referência \\
\hline Até o ginásio & $0.79 *$ & 0.110 & $1.27 *$ & 0.168 \\
\hline Até o colegial & 0.85 & 0.115 & $1.67 * * *$ & 0.218 \\
\hline Ensino superior & 0.96 & 0.148 & $2.28 * * *$ & 0.367 \\
\hline Muito religioso & 0.79 & 0.117 & $0.79 *$ & 0.109 \\
\hline Exposto à informação & $1.43 * * *$ & 0.133 & $0.85 *$ & 0.079 \\
\hline Interessado por política & $1.94 * * *$ & 0.190 & $1.63 * * *$ & 0.166 \\
\hline $\begin{array}{l}\text { Avaliação negativa da } \\
\text { economia }\end{array}$ & $0.59 * * *$ & 0.039 & $0.88^{* *}$ & 0.055 \\
\hline $\begin{array}{l}\text { Avaliação negativa do governo } \\
\text { Dilma }\end{array}$ & $0.57 * * *$ & 0.059 & $0.81^{* *}$ & 0.087 \\
\hline Forte rejeição ao PT & $0.75 * *$ & 0.096 & 0.94 & 0.110 \\
\hline Constante & 1.21 & 0.262 & $1.82^{* * *}$ & 0.391 \\
\hline Observações & & 2617 & & 2617 \\
\hline Pseudo Likelihood & 0.0903 & & 0.0418 \\
\hline Wald Qui-quadrado & 238.14 & 120.61 \\
\hline
\end{tabular}

Fonte: Elaboração própria a partir de dados do Eseb 2014.

* Significativo a 0,$10 ; * *$ Significativo a 0,$05 ; * * *$ Significativo a 0,01 .

Nossa intenção, no entanto, é dar um passo à frente e investigar que fatores são capazes de impulsionar ou frear o efeito dos perdedores sobre as atitudes democráticas. Nas análises seguintes, construímos mais três modelos multivariados idênticos aos acima, mas acrescentando, para cada um deles, um termo interativo. Para facilitar a interpretação do termo, são apresentados em gráfico seus efeitos marginais. É preciso deixar claro que 
os resultados encontrados são controlados pelas mesmas variáveis sociodemográficas e individuais que estão no modelo anterior.

No Gráfico 2, podemos ver a interação entre rejeitar o PT e o efeito dos perdedores sobre a satisfação com a democracia e a adesão a ela. Apesar da significância estatística não atingir um patamar mínimo de 0,10, a direção dos dados é sintomática e, por isso, apresentada neste artigo. Pode-se ver que os perdedores que rejeitam o PT têm uma queda maior na satisfação com a democracia. Ou seja, quem rejeita o PT tem uma probabilidade maior de estar insatisfeito com a democracia do que os perdedores que não rejeitam.

Mais importante, no entanto, é o efeito sobre a adesão à democracia. Enquanto os vencedores que rejeitam o PT tendem a reforçar seus laços com a democracia, os perdedores que rejeitam o PT tendem a abandoná-la. Ou seja, a forte rejeição ao partido potencializa os efeitos de ser um perdedor no que tange ao apoio à democracia.

\section{Gráfico 2 \\ Efeitos marginais dos perdedores e vencedores sobre a satisfação com a democracia e a adesão a ela por rejeição ao PT}
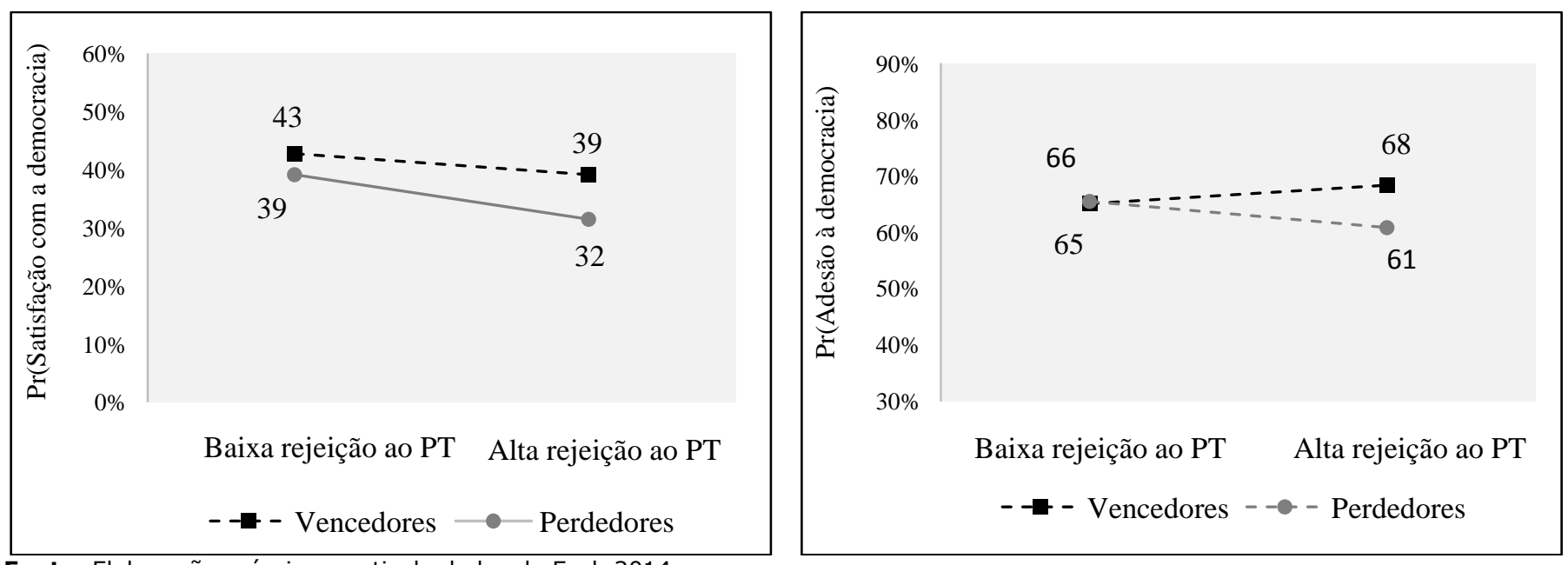

Fonte: Elaboração própria a partir de dados do Eseb 2014.

Um segundo efeito testado foi o dos eleitores que vivem no estado de São Paulo. No modelo anterior, chamou a atenção o fato de que os eleitores paulistas são mais autoritários do que a média no restante dos demais estados do país. A contradição estaria no fato de que justamente no estado mais moderno e desenvolvido do país é onde encontramos o maior número de pessoas dispostas a abrir mão do regime democrático.

Mas os efeitos de viver em São Paulo estariam só nessa relação direta? O Gráfico 3 mostra que não. Apesar de não haver diferenças no efeito dos perdedores sobre a satisfação com a democracia, existe um efeito sobre a adesão ao regime: os perdedores que vivem em São Paulo têm uma probabilidade menor de aderir à democracia. Isso 
significa que, além do efeito direto, viver em São Paulo tem também um efeito indireto sobre a não adesão à democracia, uma vez que o gap entre perdedores e vencedores fica maior.

\section{Gráfico 3 \\ Efeitos marginais dos perdedores e vencedores sobre a satisfação com a democracia e a adesão a ela por viver em São Paulo}
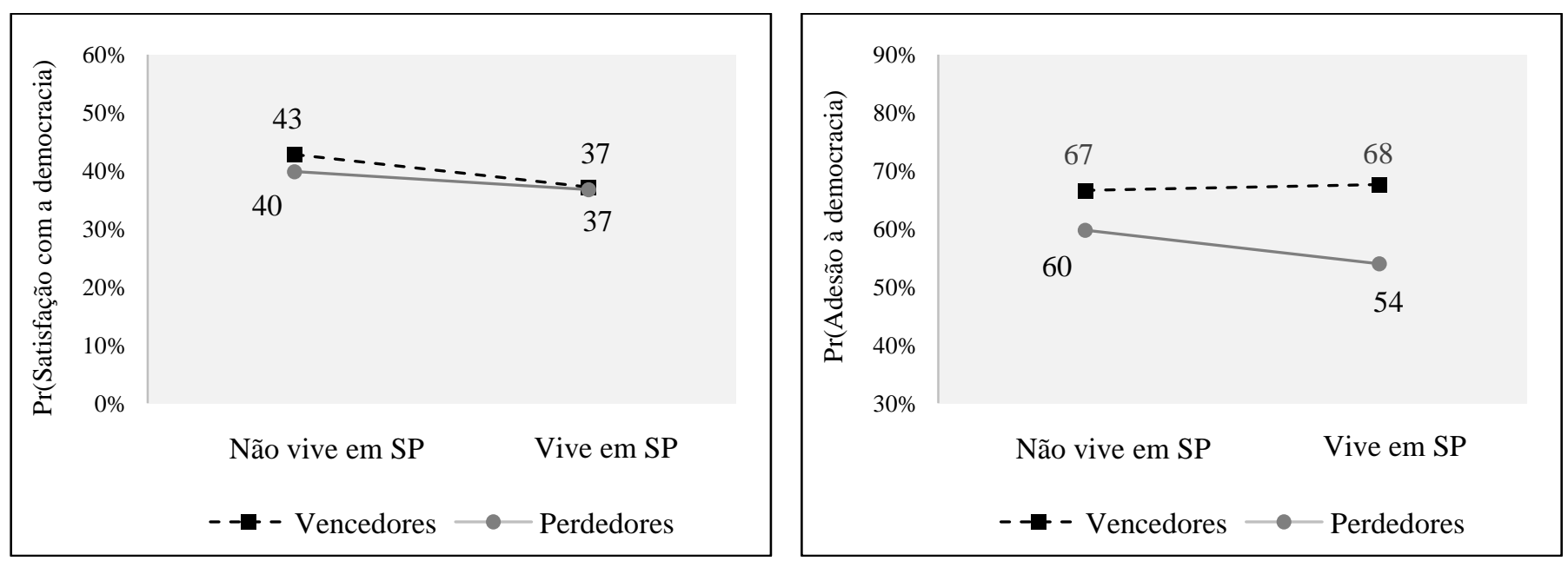

Fonte: Elaboração própria a partir de dados do Eseb 2014.

Por fim, uma terceira variável testada foi o efeito da avaliação da economia. Conforme informações do Gráfico 4, não restam dúvidas de que a má avaliação da economia interage com a derrota dos eleitores. Em primeiro lugar, podemos notar que a má avaliação econômica diminui a satisfação com o regime democrático, seja para vencedores, seja para perdedores. Ocorre que esse efeito é ainda maior entre estes últimos. Ou seja, para quem perdeu as eleições, a avaliação de que a economia não vai bem aumenta ainda mais a probabilidade de insatisfação.

O resultado mais surpreendente, no entanto, é que os vencedores que avaliam mal a economia têm forte queda em termos de adesão à democracia. Enquanto os perdedores têm uma variação marginal e até mesmo positiva, quem venceu as eleições passa, de 0,71 de adesão entre os que a avaliam como boa, para 0,59 entre os que a avaliam como ruim. Uma queda significativa de 0,12 para a adesão ao regime democrático.

Embora isso exija mais estudos, especialmente em painel, pode-se sugerir aqui um efeito de frustração. Na medida em que o vencedor espera que as coisas melhorem, uma avaliação negativa pode frustrá-lo, atingindo suas atitudes em relação à democracia, não só em termos do seu bom desempenho, como também em relação ao seu apoio. 


\section{Gráfico 4 \\ Efeitos marginais dos perdedores e vencedores sobre a satisfação e a adesão em relação à democracia por avaliação da economia (\%)}
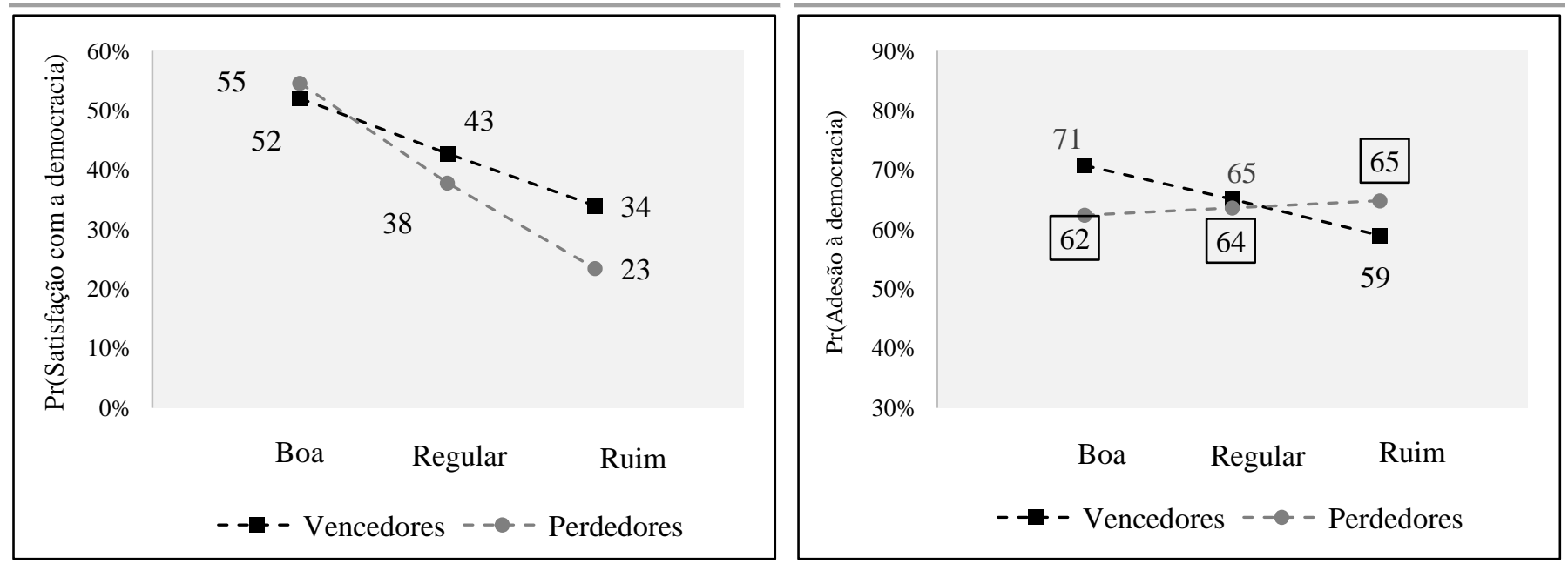

Fonte: Elaboração própria a partir de dados do Eseb 2014.

Sintetizando os resultados encontrados, podemos sugerir algumas implicações para a teoria de comportamento político, tendo em vista o caso brasileiro. Uma primeira consideração importante é que os perdedores não aderem menos à democracia do que os vitoriosos. Esse é um dado animador, tendo em vista a preocupação de que são justamente eles, os perdedores, os mais motivados (em tese) a romper o "pacto democrático".

Por outro lado, observamos que a derrota tem efeitos negativos sobre a satisfação com a democracia. Ou seja, os perdedores são mais insatisfeitos que os vencedores. Para interpretar esse resultado, é importante considerar a distinção conceitual entre apoio difuso e específico, elaborada por Easton (1965) e retomada por outros autores (Norris, 1999; Dalton, 2004; Booth e Seligson, 2009). O fato de não estar satisfeito com a democracia não implica, necessariamente, rejeição ao sistema enquanto conjunto de princípios. Por isso, é perfeitamente possível que as pessoas façam uma avaliação negativa de como a democracia funciona, sem deixarem de ser, por isso, democratas.

Tendo em vista essa distinção, não consideramos que o efeito negativo dos perdedores sobre a satisfação com a democracia seja um dado alarmante. De fato, é perfeitamente possível, e até mesmo esperado, que aqueles que não têm o representante de sua preferência eleito tenham uma postura mais crítica com o funcionamento do regime.

Outra descoberta importante é que algumas variáveis interagem com as condições assumidas por perdedores e vencedores, ampliando seus efeitos. Nesse sentido, encontramos que a forte rejeição ao PT e o fato de viver em São Paulo aumenta o gap 
entre vencedores e perdedores. Ou seja, na presença dessas condições, as probabilidades de adesão à democracia são mais baixas entre os perdedores e mais altas entre os vencedores.

Vimos ainda que a avaliação da economia cumpre um papel fundamental nessa dinâmica. De forma geral, a avaliação negativa afeta ambos os eleitores, entretanto, seu efeito é mais forte entre os perdedores. Por outro lado, os vencedores que enxergam que a economia vai mal passam a aderir menos à democracia do que os próprios perdedores. Ou seja, parece haver um efeito de frustração que atinge o próprio regime.

\section{Considerações finais}

Em 2015, a democracia brasileira completou 30 anos desde sua reorganização em meados dos 1980. Desde então acalorado debate vem sendo desenvolvido sobre a capacidade de esse regime prosperar de forma cada vez mais efetiva em países da chamada terceira onda democrática, resultando em ampla literatura (Braga e Acuña Chaverri, 2015). Contudo, os dados encontrados neste artigo lançam uma importante contribuição para uma literatura ainda pouco explorada no Brasil. De forma geral, os achados da literatura internacional foram aqui confirmados, revelando, em certo sentido, o quanto nossa democracia caminhou. De fato, existe um efeito importante provocado pela condição de perdedor ou vencedor das eleições presidenciais, mesmo quando essa condição é controlada por fatores demográficos e sociais, e avaliação econômica, de governo e partidária.

Procuramos também dar um passo a mais, desvendando algumas das dinâmicas por trás desse efeito, mostrando como a rejeição ao PT, o fato de viver em São Paulo e a avaliação da economia acabam potencializando esses efeitos.

Entretanto, à guisa de conclusão, não podemos perder de vista algumas importantes limitações do artigo e, consequentemente, uma agenda futura a ser trilhada. Em primeiro lugar, é preciso se ater as limitações metodológicas da pesquisa. Uma vez que os dados são de natureza transversal, ou seja, com apenas um ponto no tempo, não é possível tirar conclusões mais robustas sobre as mudanças de atitude ao longo do tempo.

Seria importante que, em pesquisas futuras, essa limitação fosse superada a partir de uma análise temporal dos dados. Nesse caso, seria possível captar em que medida as relações aqui observadas são pertinentes em outros momentos e conjunturas eleitorais. Igualmente relevantes são as pesquisas com dados em painel. Nesse caso seria possível observar, para um mesmo indivíduo, se houve ou não mudança a partir da vitória ou derrota nas eleições. Em suma, esses diferentes desenhos - série histórica e painel - de pesquisa seriam um importante avanço no sentido de reforçar (ou refutar) os dados aqui encontrados. 
VENCEDORES E PERDEDORES NAS ELEIÇÕES PRESIDENCIAIS DE 2014

Maria do Socorro Sousa Braga - Professora e pesquisadora no Departamento de Ciências Sociais, Programa de Pós-Graduação em Ciência Política, Universidade Federal de São Carlos. E-mail: <msbraga@ufscar.br>.

Gabriel Avila Casalecchi - Pesquisador do Centro de Estudos de Comportamento Político (Cecomp). Departamento de Ciência Política, Instituto de Filosofia e Ciências Humanas, Universidade Federal de Minas Gerais. E-mail: <gacasalecchi@gmail.com>.

\section{Referências bibliográficas}

Alvarez, M., et al. "Classifying political regimes". Journal of International Comparative Development, n० 31, pp. 3-36, 1996.

ANDERSON, C. J.; GUILLORY, C. A. "Political institutions and satisfaction with democracy: a cross-national analysis of consensus and majoritarian systems". The American Political Science Review, vol. 91, no 1, pp. 66-81, 1997.

Anderson, C. J.; LOTempio, A. J. "Winning, losing and political trust in America". British Journal of Political Science, vol. 32, no 2, p. 335-351, 2002.

Anderson, C. J.; Mendes, S. M. "Learning to lose: election outcomes, democratic experience and political protest potential". British Journal of Political Science, vol. 36, p. 91-111, 2005.

AnDERSON, C. J., et al. Losers' consent: elections and democratic legitimacy. Oxford: Oxford University Press, 2005.

BobBio, N. Liberalismo e democracia. São Paulo: Brasiliense, 1990.

Booth, J.; Seligson, M. A. The legitimacy puzzle: democracy and political support in eight Latin American nations. Cambridge, UK: Cambridge University Press, 2009.

BRAGA, M. S. S. O processo partidário-eleitoral brasileiro: padrões de competição política (1982-2002). São Paulo: Humanitas/Fapesp, 2006.

"Eleições e democracia no Brasil: a caminho de partidos e sistema partidário institucionalizados". Revista Brasileira de Ciência Política, Brasília, no 4, pp. 43-73, 2010.

Braga, M. S. S.; Acuña ChaverRi, I. A. "El fortalecimiento de la democracia en Brasil y los retos de la observación electoral". América Latina Hoy, Salamanca, no 70, ago. 2015.

Cesop. "Tendências: Eseb-CSES 2010. Opinião Pública, Campinas, vol. 17, no 2, p. 516-540, nov. 2011.

COLLIER, D.; LEVITSKY, S. "Democracy with adjectives: conceptual innovation in comparative research". World Politics, vol. 49, no 3, p. 430-451, 1997.

Crozier, M.; HUNTINGton, S.; WATANuki, J. The crisis of democracy: report on the governability of democracies to the trilateral commission. New York: New York University Press, 1975.

DAHL, R. A. Poliarquia: participação e oposição. São Paulo: Edusp, 1997.

DALTON, R. J. Democratic challenges, democratic choices: the erosion of political support in advanced industrial democracies. Oxford: Oxford University Press, 2004.

DIAMOND, L. Developing democracy: towards consolidation. Baltimore, MD: Johns Hopkins University Press, 1999. 
EASTON, D. A system analysis of political life. New York: Wiley, 1965.

HAIR JR., J., et al. Multivariate data analysis. New Jersey: Prentice Hall, 2009.

LIJPHART, A. Modelos de democracia: desempenho e padrões de governo em 36 países. Rio de Janeiro: Civilização Brasileira, 1999.

MAINWARING, S.; BRINKS, D.; PÉREZ-LiñáN, A. "Classifying political regimes in Latin America, 19451999". Studies in Comparative International Development, vol. 36, nº 1, p. 37-65, 2001.

MCAllister, I. The economic performance of governments. In: NoRRIS, P. (ed.). Critical citizens. Global support for democratic governance. Oxford, UK: Oxford University Press, pp. 204-216, 1999.

MisHLER, W.; ROSE, R. Five years after the fall: Trajectories of support for democracy in postcommunist Europe. In: NoRRIS, P. (ed.). Critical citizens. Global support for democratic governance. Oxford, UK: Oxford University Press, pp. 78-103, 1999.

. "Political support for incomplete democracies: realist vs. idealist theories and measures". International Political Science Review, vol. 22, p. 303-320, 2001.

Moisés, A. J.; CARneiro, G. P. "Democracia, desconfiança política e insatisfação com o regime - o caso do Brasil". Opinião Pública, Campinas, vol. 14, nº 1, pp. 1-42, jun. 2008.

NORRIS, P. Critical citizens. Global support for democratic government. Oxford, UK: Oxford University Press, 1999.

O'DonnelL, G.; SCHMITTER, P. C. Transições do regime autoritário: primeiras conclusões. São Paulo: Vértice/Revista dos Tribunais, 1988.

RenNó, L. R., et al. Legitimidade e qualidade da democracia no Brasil. Uma visão da cidadania. São Paulo/Nashville; Intermeios/Lapop, 2011.

SARTORI, G. Theory of democracy revisited. Chatham: Chatham House, 1987.

Singh, S. P.; Karakoç, E.; Blais, A. "Differentiating winners: how elections affect satisfaction with democracy". Electoral Studies, vol. 31, no 1, p. 201-211, 2012.

TelLes, M. "O que os protestos trazem de novo para a política brasileira?". Em Debate, Belo Horizonte, vol. 7, no 2, p. 7-14, abr. 2015.

VAIRO, D. "El 'consenso de los perdedores' y la legitimidad de la democracia en América del Sur". Política y Gobierno, vol. XIX, no 1, pp. 19-30, 2012.

\section{Resumo}

Vencedores e perdedores nas eleições presidenciais 2014: o efeito da derrota nas urnas sobre a satisfação e o apoio em relação à democracia no Brasil

Nas últimas duas décadas do século passado a democracia estabeleceu-se como regime hegemônico em várias partes do mundo. Teoricamente, essas democracias funcionam segundo preceitos constitucionais originados de consenso normativo resultante de negociação entre forças políticas que legitimam, assim, o processo de escolha de governantes. Ou seja, deve haver consenso mínimo sobre as regras subjacentes à escolha dos governantes e, posteriormente, adesão aos resultados de todos os atores envolvidos. Consequentemente, um importante sinal do quão legítima é a democracia de um 
país é o comportamento dos seus perdedores. Diante desse princípio democrático, este artigo parte de duas questões, tendo a democracia brasileira como estudo de caso. A primeira busca responder se a derrota nas urnas em 2014 afetou os graus de satisfação e de apoio dos perdedores em relação à democracia brasileira. Ou seja, perder as eleições fez com que os eleitores derrotados extrapolassem a crítica ao governo eleito, alcançando o próprio regime democrático e, portanto, as "regras do jogo"? Já a segunda indagação, de cunho mais explicativo, procura identificar quais condições são capazes de intensificar as características que podem aumentar ou diminuir o gap entre vencedores e perdedores no que se refere ao apoio ao regime democrático. A principal conclusão é a de que os perdedores das eleições são mais insatisfeitos com o desempenho da democracia do que os vitoriosos, porém não existem diferenças no que tange à adesão à democracia. Esse resultado ocorre mesmo quando controlado por diferentes características demográficas, sociais e individuais, entre elas a avaliação do governo Dilma Rousseff e a rejeição ao PT.

Palavras-chave: legitimidade democrática; apoio à democracia; eleições brasileiras de 2014

\section{Abstract}

Winners and losers in the presidential elections of 2014: the impact of defeat at the ballot box on satisfaction with and support for democracy in Brazil

In the last two decades of the 20th century, democracy has established itself as a hegemonic regime in many parts of the world. Theoretically, these democracies function according to constitutional precepts originating in normative consensus resulting from negotiations between political forces that legitimate the choice of representatives. In other words, a minimal consensus on the rules of the game must exist and, subsequently, adherence to the outcomes by all the players involved. Consequently, one of the signals of how legitimate a democracy is lies in the behavior of its losers. Given this democratic principle, this article seeks to answer two questions, with Brazilian democracy as a case study. The first asks if the defeat at the ballot box in 2014 affected the degree of satisfaction with and support for democracy among the losers in Brazilian democracy. In other words, did losing the election induce the losers to go beyond criticisms of the elected government to attack the democratic regime itself and, therefore, the "rules of the game"? The second question, which is more explanatory, seeks to identify the conditions under which the gap between winners and losers, in terms of support for the democratic regime, widens or narrows. The main conclusion is that the losers in elections are more unsatisfied with the functioning of democracy than the winners, although there are no differences with regard to commitment to democracy. This result occurs even when controlling for different demographic, social, and individual characteristics, including the evaluation of Dilma Rousseff's government and the rejection of the Workers' Party (PT).

Keywords: democratic legitimacy; support for democracy; 2014 Brazilian elections

\section{Resumen}

Los ganadores y perdedores en las elecciones presidenciales de 2014: el efecto de la derrota en las urnas en la satisfacción y el apoyo a la democracia en Brasil

En las dos últimas décadas del siglo pasado, la democracia se ha consolidado como el régimen hegemónico en diversas partes del mundo. En teoría, estas democracias funcionan de acuerdo a preceptos constitucionales originados del consenso normativo resultante de la negociación entre las fuerzas políticas que legítima, así, el proceso de elección de los gobernantes. Es decir, tiene que haber un consenso mínimo sobre las reglas que subyacen a la elección de los gobernantes y el posterior acceso a los resultados de todas las partes interesadas. En consecuencia, una señal importante de cuan legítima es la democracia de un país, es el comportamiento de los perdedores. Teniendo en cuenta este principio democrático, este artículo se basa en dos cuestiones retomando la democracia brasileña como un estudio de caso. La primera trata de responder si la derrota en las urnas en 2014 afectó el grado de satisfacción y de apoyo de los perdedores en relación a la democracia brasileña. En otras palabras, ¿perder las elecciones hizo que los votantes derrotados extrapolaran la crítica al gobierno electo, alcanzando el régimen democrático en sí y, por lo tanto, las "reglas del juego"? La 
segunda pregunta, de naturaleza más explicativa, busca identificar qué condiciones son capaces de mejorar las características que pueden aumentar o disminuir la brecha entre ganadores y perdedores cuando se trata de apoyar al régimen democrático. La principal conclusión es que los perdedores de las elecciones no están satisfechos con el desempeño de la democracia de los vencedores, pero no hay diferencias con respecto a la adhesión a la democracia. Este resultado se produce incluso cuando se controla por diferentes características demográficas, sociales e individuales, incluyendo la evaluación del gobierno de Dilma Rousseff y el rechazo del PT.

Palabras clave: la legitimidad democrática, apoyo a la democracia, las elecciones brasileñas de 2014, Brasil

\section{Résumé}

Les gagnants et les perdants des élections présidentielles de 2014: l'effet de la défaite dans les urnes sur la satisfaction et le soutien à la démocratie au Brésil

Au cours des deux dernières décennies du siècle dernier, la démocratie s'st établie comme le régime hégémonique dans diverses parties du monde. Théoriquement, ces démocraties fonctionnent selon des dispositions constitutionnelles résultant de la négociation de consensus normatif entre les forces politiques qui légitiment, de la sorte, le processus du choix des dirigeants. Autrement dit, il doit y avoir un consensus minimal sur les règles qui sous-tendent le choix des dirigeants et l'adhésion, par la suite, aux résultats de toutes les parties prenantes. Par conséquent, un signe révélateur du degré de légitimité de la démocratie d'un pays est le comportement de ses perdants. Compte tenu de ce principe démocratique, cet article est basé sur deux questions, la démocratie brésilienne constituant une étude de cas. La première cherche à savoir si la défaite électorale en 2014 a affecté le degré de satisfaction et de soutien des perdants envers la démocratie brésilienne. En d'autres termes, le fait $d$ 'avoir perdu les élections n'a-t-il pas poussé les électeurs vaincus à généraliser la critique envers le gouvernement élu, atteignant le régime démocratique lui-même et, par conséquent, les "règles du jeu"? La deuxième question, de nature plus explicative, cherche à identifier quelles sont les conditions en mesure d'améliorer les caractéristiques qui peuvent augmenter ou diminuer l'écart entre les gagnants et les perdants quand il s'agit de soutenir le régime démocratique. La principale conclusion est que les perdants des élections sont moins satisfaits de la performance de la démocratie que les vainqueurs, mais il n'y a aucune différence en ce qui concerne le respect de la démocratie. Ce résultat se confirme même lorsqu'il est contrôlé par différentes caractéristiques démographiques, sociales et individuelles, y compris l'évaluation du gouvernement Dilma Rousseff et le rejet du PT.

Mots clés: la légitimité démocratique, le soutien à la démocratie, les élections brésiliennes de 2014

Artigo submetido à publicação em março de 2016. Versão final aprovada em novembro de 2016. 